Ouachita Baptist University

Scholarly Commons@Ouachita

\title{
Parenting Children with Down Syndrome: An Analysis of Parenting Styles, Parenting Dimensions, and Parental Stress
}

\author{
B. Allyson Phillips \\ Ouachita Baptist University, phillipsa@obu.edu
}

Follow this and additional works at: https://scholarlycommons.obu.edu/articles

Part of the Cognitive Psychology Commons, and the Developmental Psychology Commons

\section{Recommended Citation}

Phillips, B. Allyson, "Parenting Children with Down Syndrome: An Analysis of Parenting Styles, Parenting Dimensions, and Parental Stress" (2017). Articles. 126.

https://scholarlycommons.obu.edu/articles/126 
PARENTING CHILDREN WITH DOWN SYNDROME: AN ANALYSIS OF PARENTING STYLES, PARENTING DIMENSIONS, AND PARENTAL STRESS

\author{
B. Allyson Phillips ${ }^{\mathrm{a}}$ \\ Frances Conners ${ }^{\mathrm{b}}$ \\ Mary Elizabeth Curtner-Smith ${ }^{\mathrm{b}}$
}

aPh.D., Assistant Professor, Ouachita Baptist University, Arkadelphia, AR, 71998, USA

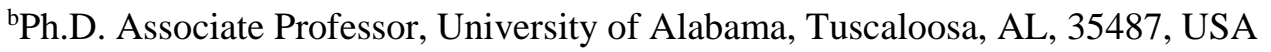

Corresponding Author:

B. Allyson Phillips, Ph.D., Assistant Professor

Email address: phillipsa@obu.edu

Ouachita Baptist University

Department of Psychology

410 Ouachita Street

Arkadelphia, AR 71998 


\begin{abstract}
Background: Effective parenting is vital for a child's development. Although much work has been conducted on parenting typically developing children, little work has examined parenting children with Down syndrome. Aims: The purpose of the current study was to compare the parenting styles and dimensions in mothers of children with DS and mothers of TD children. Methods and Procedures: Thirty-five mothers of children with DS and 47 mothers of TD children completed questionnaires about parenting, parental stress, child behavior problems, and child executive function. Outcomes and Results: We found that mothers of children with DS use an authoritative parenting style less and a permissive parenting style more than mothers of TD children. Additionally, we found that mothers of children with DS use reasoning/induction and verbal hostility less and ignoring misbehavior more than mothers of TD children. All of these differences, except for those of reasoning/induction, were at least partially accounted for by the higher levels of parental stress in the DS group. Conclusions and Implications: Parenting interventions should be focused on reducing parental stress and training parents to parent under stress in an effort to improve parenting techniques, which would, in theory, improve longterm child outcomes for children with DS.
\end{abstract}

Keywords: Down syndrome, parenting, parental stress, intellectual disability 


\section{What this paper adds?}

The current study is the first study to fully examine parenting styles and dimensions in mother of children with Down syndrome (DS) in comparison to parents of typically developing (TD) children. Both parenting styles and dimensions were measured in an effort to gain the most complete picture of parenting children with DS. The study highlights both differences and similarities in parenting between mothers of children with DS and mothers of TD children, offering insight into potential parenting interventions for parents of children with DS. The current study also examined the effect of parental stress on parenting styles and dimensions. Repeatedly, stress has been found to be higher in mothers of children with DS than in mothers of TD children, and the current study directly links this increased stress to differences in parenting. 


\section{Parenting Children with Down Syndrome: An Analysis of Parenting Styles, Parenting Dimensions, and Parental Stress}

Effective parenting is vital for a child's intellectual, physical, social, and emotional development. Although much work has been conducted on parenting typically developing (TD) children, little work has examined parenting children with Down syndrome (DS). However, parenting has a major influence on of a child's development regardless of the child's intellectual functioning. The current study compared parenting in mothers of children with DS to mothers of TD children to gain a better understanding of the role parents play within the DS population.

\subsection{Parenting Styles and Dimensions}

Baumrind's (1971) development of parenting styles provided a framework from which subsequent parenting research was shaped. From this work, she developed three parenting stylesauthoritative, authoritarian, and permissive. The different parenting styles are indicative of varying parental characteristics that are used to socialize children, and each parenting style is a particular combination of parenting responsiveness and demandingness (Baumrind, 1996). Baumrind's three parenting styles have consistently predicted child outcomes including social competence, academic performance, psychosocial development and problem behavior (e.g., Baumrind, 1991; Weiss \& Schwarz, 1996).

Authoritative parents stress parental control through the use of warm, responsive parenting by providing explanations, treating the child as an individual, and working to promote the child's autonomy. Such parents apply firm control when necessary but are not overly restrictive; they take into consideration their child's point of view but never base the final decision solely on the child's desires. Finally, they utilize skills of reasoning, clear communication, and rational discussion when interacting with their child. Authoritative parenting has been repeatedly associated with the most positive child outcomes (e.g., Baumrind, 1991; Milevsky, Schlechter, Netter, \& Keehn, 2007; Steinberg, Lamborn, Darling, Mounts, \& Dornbusch, 1994). Authoritarian parents emphasize parental control by demanding obedience, frequently using punishment, and providing little warmth, affection, or nurturance. Such parents maintain a rigid, 
absolute standard for their children and value obedience above all else; they utilize punitive and forceful measures in times when the children's belief contradicts their own. They frequently restrict the child's autonomy and engage in limited communication with the child, instead preferring that the child simply accept whatever they say to be true. Authoritarian parenting is associated with several negative outcomes including low self-esteem, decreased happiness, decreased academic success, increased alcohol and drug use, and increased anxiety (e.g., Baumrind, 1991; Furnham \& Cheng, 2000; Wolfradt, Hempel, \& Miles, 2003). Permissive parents have limited parental control and, while they are warm, they place few demands on their children. Such parents completely accept their children's desires and actions and require little of their children in terms of household responsibility and obedient behavior. They attempt to use reason and discuss family decisions and rules with their children but never apply power to accomplish parenting goals. Permissive parenting is associated with more negative child outcomes including decreased self-control, self-reliance, and academic success (e.g., Dornbusch et al., 1987; Furnham \& Cheng, 2000).

A common critique of Baumrind's parenting styles is that parents may not perfectly fit into one style; rather, one's overarching pattern of parenting may exhibit aspects of more than one style. To provide a more detailed understanding of parenting techniques, some researchers examine parenting dimensions instead of styles. Parenting dimensions piece apart aspects of each parenting style, such as parental warmth or hostility, and measure these aspects on a continuum where parents can be high or low on each dimension (Skinner, Johnson, \& Snyder, 2005). While consensus has yet to be reached on the exact number and name of the parenting dimensions, research has repeatedly found support for the existence of dimensions such as warmth, hostility, involvement, ignoring, directiveness, and autonomy as well as the use of these dimensions to predict child well-being (for review, see Skinner et al., 2005). Further, factor analyses have confirmed that parenting styles break down into reliable parenting dimensions (e.g., Olivari, Tagliabue, \& Confalonieri, 2013; Robinson, Mandaleco, Olsen, \& Hart, 1995). Examining parenting at the more detailed dimensional level should allow for a clearer understanding of 
parenting for researchers, reducing theoretical ambiguity and seemingly inconsistent findings and improving communication with parents about what child rearing practices are most beneficial.

\subsection{Parenting Children with Intellectual Disability}

Parenting styles and dimensions have been discussed at length in parents of TD children, but limited attention has been granted to parenting children with intellectual disability (ID). ID is characterized by both intellectual deficits and adaptive functioning impairments with onset during the developmental period (American Psychiatric Association, 2013). Individuals with ID typically have an IQ of 70 or below and impairments in one or more aspect of daily life such as communication, social/interpersonal skills, academic skills, work, or personal independence.

Research has repeatedly found that parents of children with ID show higher stress levels than parents of TD children (Baxter, Cummins, \& Yiolitis, 2000; Hauser-Cram, Warfield, Shonkoss, \& Krauss, 2001; Norlin \& Broberg, 2013; Oelofsen \& Richardson, 2006). Much of this added stress comes from experiences of increased child behavior problems (e.g., Meppelder, Hodes, Kef, \& Schuengel, 2015; Sloper, Knussen, Turner, \& Cunningham, 1991), greater care-giving demands (Crnic, Friedrich, \& Greenberg, 1983; Plant \& Sanders, 2007), increased financial burdens (Parish, Seltzer, Greenberg, \& Floyd, 2004; Quine \& Pahl, 1991), negative interactions with professionals and school systems (Blacher \& Hatton, 2007), and lack of both formal and informal support (Douma, Dekker, \& Koot, 2006; Turnball \& Ruef, 1996).

Much work has been conducted examining the well-being and family functioning of parents of children with ID, but only a few studies have explored their actual parenting. Woolfson and Grant (2006) found that parents of younger children with DD (ages 3-5 years) used authoritative parenting more often than parents of younger TD children but that parents of older children with DD (ages 9-11 years) used authoritative parenting less than parents of older TD children. Their results suggested that parenting style might be a moderator of the differences in groups on parental stress with parents of children with DD exhibiting greater stress than parents of TD children. They believe that utilizing authoritative parenting techniques may be exceptionally challenging for parents of children with DD due to the increased 
demands of the child's disability, the need to reiterate expectations and explanations to the child, and the little success achieved with such techniques. Parents may experience increased stress when trying to apply authoritative parenting, consequently, as the children get older, parents may decide to implement a less taxing parenting style as a way of coping with daily demands. Therefore, we see authoritative parenting being used less with the older children with DD but not the younger children with DD.

Other researchers have described circumstances that may diminish the use of authoritative parenting including decreased feelings of maternal competency in child-rearing abilities (Haldy \& Hanzlik, 1990), greater child care needs and behavior problems (Floyd \& Phillippe, 1993; Roberts \& Lawton, 2001; Wiggs \& Stores, 1996), and the low expectations society has of individuals with intellectual and developmental disabilities (Woolfson, 2004). For example, the societal view that individuals with disabilities will always be dependent on others may cause parents to become overprotective and limiting in their autonomy granting. Green, Caplan, and Baker (2013) found that mothers of children with DD attempted to control their child in a way that was interfering and intrusive more than twice as much as mothers of TD children. After accounting for the child's developmental level, interference control was significantly predictive of lower adaptive and social skills for the children with DD but not TD children. Due to all of these factors, parents might be utilizing a permissive or authoritarian parenting style instead of an authoritative style as a method of coping with the child's disability and the increased stress in their lives.

\subsection{Parenting Children with Down Syndrome}

Down syndrome is the most common genetic disorder that results in ID and is caused by an extra copy of chromosome 21. Based on mental age comparisons, speech, language, and verbal short-term memory are all areas of clear impairment in DS (Chapman \& Hesketh, 2000), but individuals with DS do not exhibit as many adaptive behavior problems as those with non-DS ID (Chapman \& Hesketh, 2000). This unique phenotype makes studying parenting within DS essential since results might not be similar to other etiologies of ID or mixed-etiology ID samples. 
Recent research has found distinctions between parenting children with DS and parenting children with non-DS ID. Specifically, parents of children with DS report less stress, depression, and pessimism than parents of children with non-DS ID (Abbeduto et al., 2004; Fidler, Hodapp, \& Dykens, 2000; Olsson \& Hwang, 2003). This has been referred to as the "Down syndrome advantage" (Hodapp, Ly, Fidler, \& Ricci, 2001). Several factors may influence this "advantage" including the positive personality characteristics of individuals with DS, parents' increased understanding of the nature and cause of DS, available support systems for parents, greater maturity of mothers, and higher family socioeconomic statuses (Hodapp, 2002).

Although distinctions exist between parents of children with DS and parents of children with nonDS ID, a similar pattern of results is found when making DS-TD comparisons as when making ID-TD comparisons, though the DS-TD differences may be smaller than the ID-TD differences. That is, parents of children with DS report increased stress (Dabrowska \& Pisula, 2010; Roach, Orsmond, \& Barratt, 1999), depression (Roach et al., 1999; Scott, Atkinson, Minton, \& Bowman, 1997), caregiving demands (Roach et al., 1999), and child behavior problems (Cuskelly \& Dadds, 1992; Roach et al., 1999) compared to parents of TD children. Additionally, stress for parents of children with DS has been shown to increase over the early childhood years as the demands associated with raising a child with DS increase (Eisenhower, Baker, \& Blacher, 2005; Hauser-Cram et al., 2001; Most, Fidler, Booth-Laforce, \& Kelly, 2006). Therefore, children with DS appear in some ways to be easier to parent than children with other intellectual disabilities (however, see Cahill \& Glidden, 1996; Stoneman, 2007), but parents of children with DS still report greater difficulties than parents of TD children.

No known studies have examined parenting styles in parents of children with DS, and only two studies to date have examined parenting dimensions. Gilmore and Cuskelly (2012) sampled 25 mothers of children with DS and tested them at two time points, first when the child was 4-6 years old and again when the child was 11-15 years old. They measured respect for autonomy, control, consistency, childcenteredness, and detachment. They found all of the parenting dimensions to be stable across time except for respect for autonomy, which displayed a significant increase from Time 1 to Time 2 . Further, they 
found that mothers utilized greater autonomy and less detachment when their child exhibited many positive, socially desirable behaviors, but that mothers utilized less autonomy and greater detachment when the child exhibited many negative, socially undesirable behaviors.

In a second study of parenting dimensions, Blacher, Baker, and Kaladjian (2013) observed and systematically coded positive parenting (i.e., positive affect, sensitivity, stimulation of cognition, and the reverse coding of detachment) and negative parenting (i.e., negative affect and intrusiveness) in mothers of children with DS, autism, cerebral palsy, undifferentiated developmental delay, and TD. They found that mothers of TD children showed the lowest ratings of negative parenting. They theorized that mothers of children with DS exhibited more behaviors that rated high on intrusion because of the intervention techniques they were taught to use with their children. Many interventions encourage the use of directive statements to refocus child and reduce behavior problems, and the coding system used in the study did not differentiate between appropriate direction and true intrusion. Additionally, they found that positive parenting was highest in mothers of children with DS and attributed this increase in positive parenting to the child's positive personality characteristics and increased compliance and self-regulation in comparison to children with other types of disabilities. Such characteristics may cause parents to show their child greater positive regard, warmth, and affection.

\subsection{Purpose of the Current Study and Hypotheses}

The current study is the first study to fully examine parenting styles and dimensions in mothers of children with DS in comparison to parents of TD children. Both parenting styles and dimensions were measured in an effort to gain the most complete picture of parenting children with DS and to be able to draw direct comparisons to the limited work that has been done with parenting styles (Woolfson \& Grant, 2006) and dimensions (Blacher et al., 2013; Gilmore \& Cuskelly, 2012) in the ID and DS literature. In an effort to expand Woolfson and Grant's (2006) results to a DS sample, we hypothesized that the mothers of children with DS would use less authoritative parenting than parents of TD children. Most of the parenting dimensions examined have yet to be studied in mothers of children with ID or DS, so their inclusion was exploratory. 
The current study also examined the effect of parental stress on parenting styles and dimensions. Repeatedly, stress has been found to be higher in mothers of children with DS than in mothers of TD children (Dabrowska \& Pisula, 2010; Roach et al., 1999), and this stress has been theoretically linked to differences in parenting. We hypothesized that parental stress would be higher in mothers of children with DS and that this higher level of stress would account for differences in parenting styles and dimensions. Finally, the current study included two additional contrast variables, child problem behaviors and child executive function, to see how these variables influenced parenting. Both of these variables have been linked to the increased stress parents of children with ID experience (e.g., Cuskelly \& Dadds, 1992; Roach et al., 1999) and could potentially result in differences in parenting styles and dimensions.

\section{Methods}

\subsection{Participants and Procedures}

Mothers/female guardians of children with DS and mothers/female guardians of TD children participated in this study. Participants were recruited through multiple avenues including a research participant registry, local agencies, and social media. Questionnaires were mailed to all but one mother, who participated by telephone interview. Participation took parents approximately 1 hour and 20 minutes. Of the 41 mothers in the group with DS who agreed to participate in the study, 35 completed the questionnaires $(85.37 \%)$. Children with DS averaged 9.06 years old, $S D=2.32$, Range $=5.08-12.92$ (17 males; 31 Caucasian, 2 White-Hispanic, 1 African American, 1 Other Race). Of the 49 mothers in the TD group who agreed to participate in the study, 47 completed the questionnaires (95.92\%). TD children averaged 8.06 years, $S D=1.71$, Range $=5.00-12.92(27$ males; 42 Caucasian, 4 African American, 1 Other Race).

\subsection{Measures}

2.2.1 Parenting Styles and Dimensions Questionnaire. The Parenting Styles and Dimensions Questionnaire (PSDQ; Robinson, Mandleco, Olsen, \& Hart, 2001) is a 62-item parent-response questionnaire that measures the three global parenting styles as first described by Baumrind (authoritative, 
authoritarian, and permissive) as well as eleven parenting dimensions within these styles. It was designed for use with parents of children from 4- to 12-years-old. Responses are on a Likert-scale ranging from never (1) to always (5). The authoritative style includes four dimensions assessed by 27 items: warmth and involvement, 11 items; reasoning/induction, 7 items; democratic participation, 5 items; and goodnatured-easygoing, 4 items. The authoritarian style includes four dimensions assessed by 20 items: verbal hostility, 4 items; corporal punishment, 6 items; nonreasoning and punitive strategies, 6 items; and directiveness, 4 items. The permissive style includes three dimensions assessed by 15 items: lack of follow-through, 6 items; ignoring misbehavior, 4 items; and self-confidence, 5 items. Scores for the three styles and eleven dimensions were found by finding the sum of all of the items within that style or dimension. Principle axes factor analyses were conducted to determine the grouping of items into three styles and then the grouping of the styles into eleven dimensions (Robinson et al., 1995). Adequate reliability was previously shown for each of the three styles: authoritative $=.91$, authoritarian $=.86$, and permissive $=.75$ (Robinson et al., 2001).

2.2.2 Parenting Stress Index. The short form of the Parenting Stress Index $4^{\text {th }}$ edition (PSI-4SF; Abidin, 1995) is a 36-item questionnaire used to measure the stress one experiences as a parent. It was designed for use with parents of children from 0- to 12-years-old. Each item presents a statement, and in all but three of the items, participants respond on a 5-point scale from strongly agree to strongly disagree. For the other three items, participants are given a partial statement with five options to choose from for completing that statement. For example, "I feel that I am: 1. Not a very good parent; 2. A person who has some trouble being a parent; 3 . An average parent; 4 . A better than average parent; 5 . A very good parent." The reported internal reliability for the PSI was .91, and the test-retest reliability was .84. The Total Stress Score was used in analyses with higher scores indicating higher levels of stress.

2.2.3 Child Behavior Checklist. The Child Behavior Checklist (CBCL; Achenbach \& Rescorla, 2001) is a parent-report measure of a child's behavioral and emotional problems. The 6- to 18-year-old version of the measure was used. Parents rate their child's behavior on a scale of 0 to 3 (not true, somewhat or sometimes true, very true or often true) for 113 items. The CBCL assesses both 
internalizing and externalizing behaviors including anxiety, depression, somatic complaints, social problems, thought problems, attention problems, rule-breaking behavior, and aggressive behavior. Good reliability has been reported for the CBCL (Cronbach's alpha =92-.94). The Total Behavior score was used in the current analyses.

2.2.4 Behavior Rating Inventory of Executive Function. The Behavior Rating Inventory of Executive Function (BRIEF; Gioia, Isquith, Guy, \& Kenworthy, 2000) is a parent-report measure of a child's executive function. It was designed for use with parents of children from 5- to 18-years-old and includes 86 items that are divided into two subcategories - behavioral regulation and metacognition. The behavioral regulation category assesses the child's inhibition, attention shifting, and emotional control. The metacognition category assesses the child's skills at initiating, planning/organizing, and monitoring as well as the child's working memory and organization of materials. For each item, parents are asked to designate how often their child exhibited a particular behavior in the past 6 months by selecting "Never," "Sometimes," or “Often.” Cronbach's alpha is .94 for behavioral regulation and .96 for metacognition. The global executive composite score was used in the current analyses.

\section{Results}

\subsection{Preliminary Analyses}

When data was missing from the PSDQ, the missing data was replaced by the mean of the appropriate subscale. When data was missing from the PSI, the CBCL, and the BRIEF, the measurement manual instructions were followed for missing data. The BRIEF could not be scored for 1 participant in the DS group because too many items were left unanswered. Any analyses involving the BRIEF do not include this participant. There were 6 outliers (+/- 3 standard deviations from the mean) on the PSDQ. Following the recommendations of other investigators, we changed the outlying scores the score at 3 standard deviations (Tabachnick \& Fidell, 2001). Means, standard deviations, and ranges for all variables

are listed in Table 1. Based on visual inspection of score distributions, there were no serious violations of normality. Finally, three ANOVAs were conducted to compare groups on parental stress, child behavior problems, and child executive function. As expected, the DS group had significantly higher levels of 
parental stress, $F(1,80)=9.21, p=.003, \eta_{\mathrm{p}}^{2}=.103$, significantly higher levels of child behavior problems, $F(1,80)=8.83, p=.004, \eta_{\mathrm{p}}{ }^{2}=.099$, and significantly lower levels of child executive function, $F(1,79)=39.12, p<.001, \eta_{\mathrm{p}}^{2}=.331$, than the TD group.

\subsection{Main Analyses}

3.2.1 Parenting styles. To examine differences between groups on the three parenting styles (authoritative, authoritarian, and permissive), a one-way multivariate analysis of variance (MANOVA) was conducted. The MANOVA revealed a significant difference between groups on parenting styles, Wilks' $\Lambda=0.89, F(3,78)=3.30, p=.025, \eta_{\mathrm{p}}{ }^{2}=.113$. Univariate follow-up analyses revealed that the groups were marginally significantly different on authoritative parenting, $F(1,80)=3.71, p=.058, \eta_{\mathrm{p}}{ }^{2}$

$=.044$, were significantly different on permissive parenting, $F(1,80)=6.16, p=.015, \eta_{\mathrm{p}}{ }^{2}=.071$, but did not differ on authoritarian parenting $(p=.733)$. The DS group was less authoritative and more permissive than the TD group.

To better determine whether group differences in parental stress or child factors accounted for the group differences in parenting styles, mediation analyses were run following the bootstrapping guidelines outlined by Preacher and Hayes (2008; see also Hayes, 2009). This method calculates an estimated mediated effect by randomly sampling cases from the data set. The random sampling is replicated 5000 times, and 5000 mediation effects are created and then averaged, producing a point estimate and a 95\% confidence interval for this point estimate. The mediation effect is considered significant $(p<.05)$ if the 95\% confidence interval does not include zero. Since group differences in parenting styles were only seen for authoritative and permissive parenting, only these two styles were examined in the mediation analyses. Based on the previous research discussed, parental stress especially, but also possibly child behavior problems and child executive function, may mediate differences in parenting styles. However, an assumption for mediation is that the mediators are correlated with the dependent variable. Consequently, each mediation analysis included only the mediators that correlated in a potentially 
explanatory direction with both Group and outcome variable. See the correlations for the mediation analyses in Table 2.

The first mediation analysis examined group differences in authoritative parenting with parental stress as the mediator. Results confirmed the mediating role of parental stress in the relation between group and authoritative parenting (point estimate $=3.03, \mathrm{CI}=.74$ to 6.00 ). This suggests that the lower level of authoritative parenting among parents of children with DS was accounted for by their higher level of stress.

The second mediation analysis examined group differences in permissive parenting with parental stress, child behavior problems, and child executive function as the mediators. Results of the mediation analysis found that the combined mediating role of parental stress, child behavior problems, and child executive function was not significant in the relation between group and permissive parenting (point estimate $=-1.30, \mathrm{CI}=-3.87$ to 0.76 ). When examining each mediator separately, parental stress was a significant mediator independent of child behavior problems and child executive function (point estimate $=-2.01, \mathrm{CI}=-4.43$ to -0.60$)$, but neither child behavior problems nor child executive function were significant independent mediators. Thus, parental stress is the primary mediator between group and permissive parenting. This suggests that the higher level of permissive parenting among parents of children with DS was accounted for by their higher level of stress.

3.2.2 Parenting dimensions. To examine differences between groups on parenting dimensions, two one-way MANOVAs were conducted. The first MANOVA compared differences between groups on positive parenting dimensions (warmth and involvement, reasoning/induction, democratic participation, good-natured-easygoing). The MANOVA revealed a significant difference between groups on positive parenting dimensions, Wilks' $\Lambda=0.75, F(4,77)=6.36, p<.001, \eta_{\mathrm{p}}{ }^{2}=.248$. Univariate follow-up analyses revealed that the groups were significantly different on reasoning/induction, $F(1,80)=18.61, p$ $<.001, \eta_{\mathrm{p}}{ }^{2}=.189$, but were not significantly different on warmth and involvement $(p=.686)$, democratic participation $(p=.450)$, or good-natured-easygoing $(p=.816)$. Mothers in the DS group used less 
reasoning/induction than mothers in the TD group. The second MANOVA compared differences between groups on negative parenting dimensions (verbal hostility, corporal punishment, nonreasoning and punitive strategies, directiveness, lack of follow-through, ignoring misbehavior, self-confidence) and found a significant difference between groups, Wilks' $\Lambda=0.79, F(7,74)=2.89, p=.010, \eta_{\mathrm{p}}{ }^{2}=.215$. Univariate follow-up analyses revealed that the groups were significantly different on verbal hostility, $F(1,80)=5.03, p=.028, \eta_{\mathrm{p}}^{2}=.059$, and ignoring misbehavior, $F(1,80)=7.84, p=.006, \eta_{\mathrm{p}}{ }^{2}=.089$, but were not significantly different on corporal punishment $(p=.579)$, nonreasoning and punitive strategies $(p=.653)$, directivenss $(p=.554)$, lack of follow-through $(p=.090)$, or self-confidence $(p=.201)$. Mothers in the DS group used verbal hostility less and ignoring misbehavior more than mothers in the TD group.

To better understand the relationship between group and parenting dimensions, mediation analyses were run. The first mediation analysis examined group differences in reasoning/induction with parental stress and child executive function as the mediators. Results of the mediation analysis found that the combined mediating role of parental stress and child executive function was not significant in the relation between group and reasoning/induction (point estimate $=.06, \mathrm{CI}=-1.24$ to 1.28 ). Further, when examining each mediator separately, neither mediator was significant while controlling for the other mediator. This suggests that parental stress and child executive function are not mediating the differences between groups on reasoning/induction.

The second mediation analysis examined group differences in ignoring misbehavior with parental stress and child behavior problems as the mediators. The combined mediating role of parental stress and child behavior problems was not significant in the relation between group and verbal hostility (point estimate $=-.35, \mathrm{CI}=-.96$ to .01$)$. When examining each mediator separately, parental stress was a significant mediator (point estimate $=-.42, \mathrm{CI}=-1.17$ to -0.08 ) independent of child behavior problems, but child behavior problems was not a significant independent mediator. This suggests that the higher 
level of ignoring misbehavior among parents of children with DS was partially accounted for by the higher level of parental stress.

\section{Discussion}

\subsection{Parenting Styles}

Our first major finding was that mothers of children with DS utilized authoritative parenting less and permissive parenting more than mothers of TD children. These results replicate those of Woolfson and Grant (2006) who found that parents of children with DD between the ages of 9 and 11 years used authoritative parenting less than parents of TD children. It should be noted, however, that whereas mothers of children with DS used authoritative parenting significantly less and permissive parenting significantly more than mothers of TD children, they were not at the extreme low end of authoritative parenting or the extreme high end of permissive parenting. The current study did not examine childhood outcomes; therefore, we are unable to know if the decreased use of authoritative parenting and increased use of permissive parenting resulted in negative consequences for the children with DS.

Another major finding was that differences in parenting styles between mothers in the two groups was mediated by parenting stress. Thus, the differences between mothers of children with DS and mothers of TD children in authoritative and permissive parenting can be explained by parental stress. Mothers of children with DS have higher levels of parental stress than mothers of TD children and, possibly as a result of increased stress, use authoritative parenting less and permissive parenting more than the mothers of TD children. Previous research has repeatedly shown increased levels of stress in parents of children with ID (Baxter et al., 2000; Hauser-Cram et al., 2001; Norlin \& Broberg, 2013; Oelofsen \& Richardson, 2006) and specifically in parents of children with DS (Dabrowska \& Pisula, 2010; Roach et al., 1999), but this is the first study to show that this increase in parental stress is potentially affecting parenting styles. It is possible that parents of children with DS are more likely to use permissive parenting over authoritative parenting because giving the child what he/she wants temporarily eliminates the problem behavior, which alleviates stress for a short period (see Hastings, 2002).

\subsection{Parenting Dimensions}


Our second major finding was that mothers of children with DS utilized reasoning/induction and verbal hostility less and ignoring misbehavior more than mothers of TD children. None of the other parenting dimensions showed significant differences between groups. The differences in reasoning/induction were not explained by parental stress or child executive function. It is possible that mothers of children with DS use reasoning/induction less due to the child's lower cognitive functioning. The mothers may believe that their child does not have the cognitive skills to understand explanations for disciplinary action, so they do not provide explanations. Yet, child executive function did not mediate the relation between group and reasoning/induction. It is also possible that mothers of children with DS have fewer rules and expectations for their children than mothers of TD children. Future research should examine the type of rules, expectations, and disciplinary tactics used by mothers of children with DS.

In terms of verbal hostility, parents of children with DS might not be hostile because of the characteristically pleasant personalities of children with DS (Hodapp et al., 2001). This unique phenotype of children with DS could even result in lower levels of coercion amongst parents of children with DS compared to parents of children with non-DS ID. The use of verbal hostility is linked to long-term negative child outcomes, so the limited use of verbal hostility by mothers of children with DS is advantageous for their children.

Finally, mothers of children with DS are more likely to ignore misbehavior than mothers of TD children. To some extent, this might be a behavioral management strategy parents have learned to extinguish the misbehavior. However, the mediation analyses indicated that the group difference in ignoring misbehavior was mediated by parental stress. Mothers of children with DS who are especially stressed by greater caregiving demands (Plant \& Sanders, 2007; Roberts \& Lawton, 2001), might ignore misbehavior more often, rather than actively disciplining every time the child misbehaves.

\subsection{Parental Stress}

Throughout all of the analyses, parental stress was repeatedly highlighted as a key component in differences between groups. Not only was parental stress significantly higher in mothers of children with DS than mothers of TD children, parental stress also accounted for many of the differences seen between 
groups on parenting styles and parenting dimensions. Consequently, without the differences in parental stress, the DS group might not be different from the TD group in their parenting styles and dimensions.

There is a multitude of reasons why stress is elevated for mothers of children with DS. Children with DS have increased behavior problems (Cuskelly \& Dadds, 1992; Roach et al., 1999) and are at-risk for many health-related problems (Van Allen, Fung, \& Jurenka, 1999). Parents experience greater caregiving demands (Roach et al., 1999), increased financial burdens (Parish et al., 2004; Quine \& Pahl, 1991), more issues associated with advocacy (Blacher \& Hatton, 2007), limited formal and informal support (Douma et al., 2006), and decreased feelings of maternal competency (Haldy \& Hanzlik, 1990). Since the increased stress for mothers of children with DS was associated with the decreased use of parenting techniques typically associated with positive child outcomes and increased use of parenting techniques typically associated with negative outcomes, lowering stress should possibly be the focus of parenting intervention efforts. If intervention could lower parental stress in parents of children with DS, then parents might possibly start using positive parenting techniques more and negative parenting techniques less. In turn, children with DS would presumably show long-term improvements in behavioral, social, and/or academic domains. Another approach is for parenting interventions to address parenting in the context of stress. That is, in addition to trying to reduce stress, teach parents how to cope with stress or to parent under stress.

\subsection{Limitations}

The present study has certain limitations that warrant mention. Though larger than other studies examining parenting dimensions in parents of children with DS, the sample size of the DS group was relatively small. This potentially limited the power necessary to detect a significant difference between groups. In the future, larger samples are needed. Also, all of our mothers volunteered to participate in a study on parenting, and therefore may be different in some ways from mothers who decline to participate in a study on parenting. Further, in any survey study, and possibly especially one on a topic like parenting, there is a possibility of socially desirable response bias. Either of these potential biases could account for the current study's relatively low scores on negative parenting techniques and relatively high 
scores on positive parenting techniques. Future research would benefit from including both survey and observational designs in an effort to eliminate response bias.

\subsection{Future Directions}

Little work has been previously conducted on parenting styles and dimensions in parents of children with DS; therefore, much of the current study was exploratory in nature. Our results provide a solid foundation for future work in this field. Future studies need to utilize multiple methods to find converging evidence (e.g., parent-report and observation) and compare parenting styles and dimensions across etiologies of ID. Even though our mothers of children with DS were fairly similar in parenting techniques to our parents of TD children, parents of children with non-DS ID could be different. We know that parents of children with DS are different from parents of children with non-DS ID in that they have lower levels of stress, depression, and pessimism (e.g., Abbeduto et al., 2004; Olsson \& Hwang, 2003). This "Down syndrome advantage" might account for some of our null findings, and greater differences between parents of children with ID and parents of TD children might occur when this advantage is not there. For the same reason, difference in parenting dimensions might also be found between parents of children with DS and parents of children with non-DS ID.

Longitudinal studies are also needed for two primary reasons. First, we need to understand the stability of parenting styles and dimensions across time for parents of children with DS. We know from the TD literature that many factors can influence the stability of parenting (Holden \& Miller, 1999), and we also know that stress for parents of children with DS increases as children get older (Eisenhower et al., 2005; Hauser-Cram et al., 2001; Most et al., 2006). Future studies with a larger sample size, the inclusion of a comparison group, and assessment at multiple time points would allow us to expand our understanding of the stability of parenting and determine if there are particular points in a child's life when parenting intervention is more greatly needed. Secondly, we need to know the effects that particular parenting styles and dimensions have on long-term outcomes for children with DS. Before we begin to intervene with parents of children with DS who exhibit more negative parenting techniques, we need to know that these parenting techniques are in fact negative for this population. 


\subsection{Conclusions}

We conclude that mothers of children with DS are overall using similar parenting methods as mothers of TD children. Almost all differences that do exist in parenting styles and dimensions can be accounted for by parental stress. As such, parenting interventions should be focused on reducing parental stress and training parents to parent under stress in an effort to improve parenting techniques, which would, in theory, improve long-term child outcomes for children with DS. 


\section{References}

Abbeduto, L., Seltzer, M.M., Shattuck, P., Krauss, M., Orsmond, G., \& Murphy, M.M. (2004).

Psychological well-being and coping in mothers of youths with autism, Down syndrome, or Fragile X syndrome. American Journal of Mental Retardation, 109, 237-254.

Abidin, R. (1995). Parenting Stress Index ( $3^{\text {rd }}$ ed.). Odessa, Florida: Psychological Assessment Resources.

Achenbach, T.M., \& Rescorla, L.A. (2001). Manual for the ASEBA School-age Forms and Profiles. Burlington, VT: University of Vermont, Research Center for Children, Youth, and Families.

American Psychiatric Association (2013). Diagnostic and statistical manual of mental disorders (5 ${ }^{\text {th }}$ ed.). Washington, DC: American Psychiatric Publishing.

Baumrind, D. (1971). Current patterns of parental authority. Developmental Psychology Monogragh, 4, 1103.

Baumrind, D. (1991). The influence of parenting style on adolescent competence and substance abuse. Journal of Early Adolescence, 11, 56-95.

Baumrind, D. (1996). The discipline controversy revisited. Family Relations, 45, 405-414.

Baxter, C., Cummins, R.A., \& Yiolitis, L. (2000). Parental stress attributed to family members with and without disability: A longitudinal study. Journal of Intellectual and

Blacher, J., Baker, B.L., \& Kaladjian, A. (2013). Syndrome specificity and mother-child interactions: Examining positive and negative parenting across contexts and time. Journal of Autism and Developmental Disorders, 43, 761-774.

Blacher, J., \& Hatton, C. (2007). Families in context: Influences on coping and adaptation. In S.L. Odom, R.H. Home, M.E. Snell, \& J. Blacher (Eds.), Handbook of Developmental Disabilities (pp. 531546). New York: Guilford Press.

Cahill, B.M., \& Glidden, L.M. (1996). Influence of child diagnosis on family and parental functioning: Down syndrome versus other disabilities. American Journal on Mental Retardation, 101, 149160. 
Chapman, R.S., \& Hesketh, L.J. (2000). Behavioral phenotype of individuals with Down syndrome. Mental Retardation and Developmental Disabilities Research Reviews, 6, 84-95.

Crnic, K.A., Friedrich, W.N., \& Greenberg, M.T. (1983). Adaptation of families with mentally retarded children: A model of stress, coping, and family ecology. American Journal of Mental Deficiency, $88,125-138$.

Cuskelly, M., \& Dadds, M. (1992). Behavior problems in children with Down's syndrome and their siblings. Child Psychology and Psychiatry, 33, 749-761.

Dabrowska, A., \& Pisula, E. (2010). Parenting stress and coping styles in mothers and fathers of preschool children with autism and Down syndrome. Journal of Intellectual Disability Research, 54, 266-280.

Dornbusch, S.M., Ritter, P.L., Leiderman, P.H., Roberts, D.F., \& Fraleigh, M.J. (1987). The relation of parenting style to adolescent school performance. Child Development, 58, 1244-1257.

Douma, J.C.H., Dekker, M.C., \& Koot, H.M. (2006). Supporting parents of youth with intellectual disabilities and psychopathology. Journal of Intellectual Disability Research, 50, 570-581.

Eisenhower, A.S., Baker, B.L., \& Blacher, J. (2005). Preschool children with intellectual disability: Syndrome specificity, behavior problems, and maternal well-being. Journal of Intellectual Disability Research, 49, 657-671.

Fidler, D.J., Hodapp, R.M., \& Dykens, E.M. (2000). Stress in families of young children with Down syndrome, Williams syndrome, and Smith-Magenis syndrome. Early Education and Development, 11, 395-406.

Floyd, F.J., \& Phillippe, K.A. (1993). Parental interactions with children with and without mental retardation: Behavior management, coerciveness, and positive exchange. American Journal on Mental Retardation, 97, 673-684.

Furnham, A., \& Cheng, H. (2000). Perceived parental behavior, self-esteem and happiness. Social Psychiatry and Psychiatric Epidemiology, 35, 463-470. 
Gilmore, L., \& Cuskelly, M. (2012). Parenting satisfaction and self-efficacy: A longitudinal study of mothers of children with Down syndrome. Journal of Family Studies, 18, 28-35.

Gioia, G.A., Isquith, P.K., Guy, S.C., \& Kenworthy, L. (2000). The Behavior Rating Inventory of Executive Function. Professional Manual. Lutz, FL: Psychological Assessment Resources.

Green, S., Caplan, B., \& Baker, B. (2013). Maternal supportive and interfering control as predictors of adaptive and social development in children with and without developmental delays. Journal of Intellectual Disability Research. doi: 10.1111/jir.12064

Haldy, M., \& Hanzlik, J. (1990). A comparison of perceived competence in child-rearing between mothers of children with Down syndrome and mothers of children without delays. Education and Training in Mental Retardation, 25, 12-141.

Hastings, R.P. (2002). Parental stress and behavior problems of children with developmental disability. Journal of Intellectual and Developmental Disability, 27, 149-160.

Hauser-Cram, P., Warfield, M.E., Shonkoff, J.P., \& Krauss, M.W. (2001). The development of children with disabilities and the adaptation of their parents: Theoretical perspectives and empirical evidence. Monographs of the Society for Research in Child Development, 66, 6-21.

Hayes, A.F. (2009). Beyond Baron and Kenny: Statistical mediation analysis in the new millennium. Communication Monographs, 76, 408-420.

Hodapp, R.M. (2002). Parenting children with mental retardation. In M.H. Bornstein (Ed.), Handbook or Parenting, $2^{\text {nd }}$ ed., Vol. 1: Children and Parenting (pp. 355-381). Mahweh, NJ: Erlbaum. Hodapp, R.M., Ly, R.M., Fidler, D.J., \& Ricci, L.A. (2001). Less stress, more rewarding: Parenting children with Down syndrome. Parenting: Science and Practice, 1, 317-337.

Holden, G.W., \& Miller, P.C. (1999). Enduring and different: A meta-analysis of the similarity in parents' child rearing. Psychological Bulletin, 125, 223-254.

Meppelder, M., Hodes, M., Kef, S., \& Schuengel, C. (2015). Parenting stress and child behavior problems among parents with intellectual disabilities: The buffering role of resources. Journal of Intellectual Disability Research, 59, 664-677. 
Milevsky, A., Schlechter, M., Netter, S., \& Keehn, D. (2007). Maternal and paternal parenting styles in adolescents: Associations with self-esteem, depression and life-satisfaction. Journal of Child and Family Studies, 16, 39-47.

Most, D.E., Fidler, D.J., Booth-Laforce, C., \& Kelly, J. (2006). Stress trajectories in mothers of young children with Down syndrome. Journal of Intellectual Disability Research, 50, 501-514.

Norlin, D., \& Broberg, M. (2013). Parents of children with and without intellectual disability: Couple relationship and individual well-being. Journal of Intellectual Disability Research, 57, 552-566.

Oelofsen, N., \& Richardson, P. (2006). Sense of coherence and parenting stress in mothers and fathers of preschool children with developmental disability. Journal of Intellectual and Developmental Disability, 31, 1-12.

Olivari, M.G., Tagliabue, S. \& Confalonieri, E. (2013). Paring style and dimensions questionnaire: A review of reliability and validity. Marriage and Family Review, 49, $465-490$.

Olsson, M.B., \& Hwang, P.C. (2003). Influence of macro structure of society on the life situation of families with a child with intellectual disability: Sweden as an example. Journal of Intellectual Disability Research, 47, 328-341.

Parish, S.L., Seltzer, M.M., Greenberg, J.S., \& Floyd, F. (2004). Economic implications of caregiving at midlife: Comparing parents with and without children who have developmental disabilities. Mental Retardation, 42, 413-426.

Plant, K.M., \& Sanders, M.R. (2007). Predictors of care-giver stress in families of preschool-aged children with developmental disabilities. Journal of Intellectual Disability Research, 51, 109-124.

Preacher, K.J., \& Hayes, A.F. (2008). Asymptotic and resampling strategies for assessing and comparing indirect effects in multiple mediator models. Behavior Research Methods, 40, 879-891.

Quine, L., \& Pahl, J. (1991). Stress and coping in mothers caring for a child with severe learning difficulties: A test of Lazarus' transactional model of coping. Journal of Community and Applied Social Psychology, 1, 57-70. 
Roach, M.A., Orsmond, G.I., \& Barratt, M.S. (1999). Mothers and fathers of children with Down syndrome: Parental stress and involvement in childcare. American Journal on Mental Retardation, 104, 422-436.

Roberts, K., \& Lawton, D. (2001). Acknowledging the extra care parents give their disabled children. Child: Care, Health, and Development, 27, 307-319.

Robinson, C.C., Mandleco, B., Olsen, S.F., \& Hart, C.H. (1995). Authoritative, authoritarian, and permissive parenting practices: Development of a new measure. Psychological Reports, 77, 819839.

Robinson, C.C., Mandleco, B., Olsen, S.F., \& Hart, C.H. (2001). The Parenting Styles and Dimensions Questionnaire. In B.F. Perlmutter, J. Touliatos, \& G.W. Holden (Eds.) Handbook of Family Measurement Techniques: Vol. 3. Instruments and Index (pp. 319-321). Thousand Oaks: Sage.

Scott, B.S., Atkinson, L., Minton, H.L., \& Bowman, T. (1997). Psychological distress of parents of infants with Down syndrome. American Journal on Mental Retardation, 102, 161-171.

Skinner, E., Johnson, S., \& Snyder, T. (2005). Six dimension of parenting: A motivational model. Parenting: Science and Practice, 5, 175-235.

Sloper, P., Knussen, C., Turner, S., \& Cunningham, C. (1991). Factors related to stress and satisfaction with life in families of children with Down syndrome. Journal of Child Psychology and Psychiatry, 32, 655-676.

Steinberg, L., Lamborn, S., Darling, N., Mounts, N., \& Dombusch, S. (1994). Over-time changes in adjustment and competence among adolescents from authoritative, authoritarian, indulgent and neglectful families. Child Development, 65, 754-770.

Stoneman, Z. (2007). Examining the Down syndrome advantage: Mothers and fathers of young children with disabilities. Journal of Intellectual Disability Research, 51, 1006-1017.

Tabachnick, B.D., \& Fidell, L.S. (2001). Using Multivariate Statistics ( ${ }^{\text {th }}$ ed.). New York: Harper Collins. 
Turnbull, A.P., \& Ruef, M. (1996). Family perspectives on problem behavior. Mental Retardation, 34, 280-293.

Van Allen, M.I., Fung, J., \& Jurenka, S.B. (1999). Health care concerns and guidelines for adults with Down syndrome. American Journal of Medical Genetics, 89, 100-110.

Weiss, L.H., \& Schwarz, J.C. (1996). The relationship between parenting types and older adolescents' personality, academic achievement, adjustment, and substance use. Child Development, 67(5), 2101-2114.

Wiggs, L., \& Stores, G. (1996). Severe sleep disturbance and daytime challenging behavior in children with severe learning disabilities. Journal of Intellectual Disability Research, 40, 518-528.

Wolfradt, U., Hempel, S., \& Miles, J.N.V. (2003). Perceived parenting styles, depersonalization, anxiety and coping behavior in adolescents. Personality and Individual Differences, 34, 521-532.

Woolfson, L. (2004). Family wellbeing and disabled children: A psychosocial model of disability-related child behavior problems. British Journal of Health Psychology, 9, 1-13.

Woolfson, L., \& Grant, E. (2006). Authoritative parenting and parental stress in parents of pre-school and older children with developmental disabilities. Child: Care, Health, and Development, 32, 177184. 
Table 1

Descriptive Statistics

\begin{tabular}{|c|c|c|c|c|c|}
\hline & & $\mathbf{N}$ & Mean & SD & Range \\
\hline \multicolumn{6}{|l|}{ TD Group } \\
\hline & CA & 47 & 8.06 & 1.71 & $5.00-12.92$ \\
\hline & Authoritative & 47 & 108.97 & 10.72 & $83-125$ \\
\hline & Authoritarian & 47 & 39.14 & 7.15 & $24-56$ \\
\hline & Permissive & 47 & 27.24 & 4.63 & $19-42.11$ \\
\hline & Warmth \& Involvement & 47 & 48.69 & 3.99 & $36.59-55$ \\
\hline & Reasoning/Induction & 47 & 29.23 & 3.40 & $21-35$ \\
\hline & Democratic Participation & 47 & 15.61 & 3.45 & $8-21.25$ \\
\hline & Good-natured-easygoing & 47 & 15.45 & 2.24 & $9-20$ \\
\hline & Verbal Hostility & 47 & 8.89 & 2.10 & $5-14$ \\
\hline & Corporal Punishment & 47 & 10.26 & 2.49 & $6-16$ \\
\hline & Nonreasoning \& & 47 & 9.37 & 2.23 & $6-15$ \\
\hline & Punitive Strategies & & & & \\
\hline & Directiveness & 47 & 10.62 & 2.32 & $6-16$ \\
\hline & Lack of Follow-through & 47 & 12.02 & 2.94 & $7-21.07$ \\
\hline & Ignoring Misbehavior & 47 & 5.91 & 1.35 & $4-9$ \\
\hline & Self-confidence & 47 & 9.36 & 2.34 & $5-15$ \\
\hline & PSI-4-SF & 47 & 68.77 & 16.56 & $38-98$ \\
\hline & CBCL & 47 & 23.93 & 17.87 & $1-81.90$ \\
\hline & BRIEF & 47 & 115.59 & 25.46 & $79-192.90$ \\
\hline \multicolumn{6}{|l|}{ DS Group } \\
\hline & $\mathrm{CA}$ & 35 & 9.06 & 2.32 & $5.08-12.92$ \\
\hline & Authoritative & 35 & 104.51 & 9.86 & $78.42-124$ \\
\hline & Authoritarian & 35 & 38.60 & 6.97 & $28-55$ \\
\hline & Permissive & 35 & 30.46 & 7.11 & $19-51$ \\
\hline & Warmth \& Involvement & 35 & 48.34 & 3.69 & $39-55$ \\
\hline & Reasoning/Induction & 35 & 25.60 & 4.22 & $16-32$ \\
\hline & Democratic Participation & 35 & 15.01 & 3.65 & $6-24$ \\
\hline & Good-natured-easygoing & 35 & 15.56 & 2.15 & $10-20$ \\
\hline & Verbal Hostility & 35 & 7.81 & 2.24 & $4-15.45$ \\
\hline & Corporal Punishment & 35 & 10.56 & 2.40 & $6-18.61$ \\
\hline & Nonreasoning \& & 35 & 9.14 & 2.38 & $6-16$ \\
\hline & Punitive Strategies & & & & \\
\hline & Directiveness & 35 & 10.94 & 2.63 & $7-16$ \\
\hline & Lack of Follow-through & 35 & 13.22 & 3.37 & $8-25.79$ \\
\hline & Ignoring Misbehavior & 35 & 6.97 & 2.06 & $4-13$ \\
\hline & Self-confidence & 35 & 10.09 & 2.73 & $5-18$ \\
\hline & PSI-4-SF & 35 & 81.91 & 22.70 & $36-140$ \\
\hline & CBCL & 35 & 37.06 & 22.10 & $4-100$ \\
\hline & BRIEF & 34 & 149.12 & 21.28 & $90-191$ \\
\hline
\end{tabular}


Table 2

Correlations

\begin{tabular}{|c|c|c|c|c|c|c|c|c|}
\hline \multicolumn{9}{|c|}{ TD Group } \\
\hline & Authoritative & Permissive & $\begin{array}{l}\text { Reasoning/ } \\
\text { Induction }\end{array}$ & $\begin{array}{c}\text { Verbal } \\
\text { Hostility }\end{array}$ & $\begin{array}{c}\text { Ignoring } \\
\text { Misbehavior }\end{array}$ & $\begin{array}{c}\text { Parental } \\
\text { Stress }\end{array}$ & $\begin{array}{c}\text { Child } \\
\text { Behavior }\end{array}$ & $\begin{array}{c}\text { Child } \\
\text { Executive } \\
\text { Function }\end{array}$ \\
\hline Authoritative & -- & $-.43 * *$ & $.81 * *$ & $-.39 * *$ & -.08 & $-.47 * *$ & .05 & -.08 \\
\hline Permissive & -- & -- & $-.44 * *$ & .20 & $.51 * *$ & $.39 * *$ & .10 & .16 \\
\hline $\begin{array}{l}\text { Reasoning/ } \\
\text { Induction }\end{array}$ & -- & -- & -- & $-.29 *$ & -.27 & -.21 & .21 & .06 \\
\hline $\begin{array}{l}\text { Verbal } \\
\text { Hostility }\end{array}$ & -- & -- & -- & -- & -.02 & $.40 * *$ & .14 & $.31 *$ \\
\hline $\begin{array}{c}\text { Ignoring } \\
\text { Misbehavior }\end{array}$ & -- & -- & -- & -- & -- & .01 & .02 & -.20 \\
\hline $\begin{array}{c}\text { Parental } \\
\text { Stress }\end{array}$ & -- & -- & -- & -- & -- & -- & $.41 * *$ & $.51 * *$ \\
\hline $\begin{array}{c}\text { Child } \\
\text { Behavior }\end{array}$ & -- & -- & -- & -- & -- & -- & -- & $.63 * *$ \\
\hline \multicolumn{9}{|c|}{$\begin{array}{c}\text { DS Group } \\
\end{array}$} \\
\hline & Authoritative & Permissive & $\begin{array}{l}\text { Reasoning/ } \\
\text { Induction }\end{array}$ & $\begin{array}{c}\text { Verbal } \\
\text { Hostility }\end{array}$ & $\begin{array}{c}\text { Ignoring } \\
\text { Misbehavior }\end{array}$ & $\begin{array}{c}\text { Parental } \\
\text { Stress }\end{array}$ & $\begin{array}{c}\text { Child } \\
\text { Behavior }\end{array}$ & $\begin{array}{c}\text { Child } \\
\text { Executive } \\
\text { Function }\end{array}$ \\
\hline Authoritative & -- & -.27 & $.83 * *$ & -.10 & $-.36 *$ & $-.38 *$ & -.19 & -.21 \\
\hline Permissive & -- & -- & -.20 & .16 & $.69 * *$ & $.50 * *$ & .28 & .25 \\
\hline $\begin{array}{l}\text { Reasoning/ } \\
\text { Induction }\end{array}$ & -- & -- & -- & -.10 & $-.35^{*}$ & -.22 & .01 & -.13 \\
\hline $\begin{array}{l}\text { Verbal } \\
\text { Hostility }\end{array}$ & -- & -- & -- & -- & .11 & $.36^{*}$ & $.53 * *$ & $.42 *$ \\
\hline $\begin{array}{c}\text { Ignoring } \\
\text { Misbehavior }\end{array}$ & -- & -- & -- & -- & -- & $.54 * *$ & .23 & .20 \\
\hline $\begin{array}{c}\text { Parental } \\
\text { Stress }\end{array}$ & -- & -- & -- & -- & -- & -- & $.66^{* *}$ & $.64 * *$ \\
\hline $\begin{array}{c}\text { Child } \\
\text { Behavior }\end{array}$ & -- & -- & -- & -- & -- & -- & -- & $.74 * *$ \\
\hline
\end{tabular}

Note: $* \mathrm{p}<.05$. $* * \mathrm{p}<.01$. 